\title{
IceCube Enhanced Hot Water Drill functional description
}

\author{
T. BENSON, ${ }^{1}$ J. CHERWINKA, ${ }^{1}$ M. DUVERNOIS, ${ }^{2}$ A. ELCHEIKH, ${ }^{3}$ F. FEYZI, ${ }^{1}$ \\ L. GREENLER, ${ }^{1}$ J. HAUGEN, ${ }^{2}$ A. KARLE, ${ }^{2}$ M. MULLIGAN, ${ }^{4}$ R. PAULOS ${ }^{1}$ \\ ${ }^{1}$ Physical Sciences Laboratory, University of Wisconsin-Madison, Stoughton, WI, USA \\ E-mail: tbenson@psl.wisc.edu \\ ${ }^{2}$ Wisconsin IceCube Particle Astrophysics Center, University of Wisconsin-Madison, Madison, WI, USA \\ ${ }^{3}$ Australian Antarctic Division, Channel Highway, Kingston, Tasmania, Australia \\ ${ }^{4}$ Space Science and Engineering Center, University of Wisconsin-Madison, Madison, WI, USA
}

\begin{abstract}
The IceCube Neutrino Observatory was constructed at the South Pole during the 2004/05 to 2010/11 austral summer seasons. IceCube transforms $1 \mathrm{~km}^{3}$ of Antarctic ice into an astrophysical particle detector composed of 86 cables (strings) of optical sensors buried deep beneath the surface. Each string required drilling a borehole $\sim 60 \mathrm{~cm}$ in diameter to a depth of $2500 \mathrm{~m}$. The $5 \mathrm{MW}$ Enhanced Hot Water Drill was designed and built specifically for this task, capable of producing the required boreholes at a rate of one hole per 48 hours. Hot-water drilling on this scale presented unique challenges and was rich in lessons learned, yielding a collection of notable developments and takeaways (e.g. fuel-saving measures, thermal modeling, firn drilling and closed-loop computer control). Descriptions of system functionality and of lessons learned from IceCube drilling are presented.
\end{abstract}

KEYWORDS: Antarctic glaciology, Arctic glaciology, polar firn, subglacial lakes

\section{INTRODUCTION}

During the 2004/05 to 2010/11 austral summers, the Enhanced Hot Water Drill (EHWD) was used to construct the IceCube Neutrino Observatory. IceCube is the world's largest neutrino detector, transforming $1 \mathrm{~km}^{3}$ of ice deep below the South Pole into a highly sensitive optical instrument (Halzen and Klein, 2010). Comprising 5160 digital optical modules (DOMs) (IceCube Collaboration, 2013), attached to 86 vertical cables frozen into the ice, it looks for astrophysical sources of very energetic neutrinos.

Because of the optical sensitivity required, the active detector volume must be transparent, clear and dark. The Amundsen-Scott South Pole Station, operated by the United States Antarctic Program, provides logistical access to a large volume of clear, deep ice, making the South Pole an ideal location for the IceCube detector. The instrumented depth is 1450-2450 m (IceCube Collaboration, 2009), and deployment of the DOMs required a minimum borehole diameter of $45 \mathrm{~cm}$.

Large-access holes were required at a high production rate. Hot-water drilling was selected as the best method due to its inherent speed. Indeed, hot-water drilling is the only feasible technology to provide rapid access to the deep ice on this scale. Additionally, leaving the boreholes waterfilled during drilling allowed for the deployed instrumentation to become frozen in place and optically coupled with the surrounding ice sheet.

Hot-water drilling in this case involved a drilling phase to create the initial hole, followed by an upward reaming phase to give the hole a targeted profile. Hole diameter was oversized to compensate for closure from freeze-back to provide sufficient time to deploy instrumentation, with contingency time for delays. The elapsed duration from the end of drilling until the hole closes to below specification is referred to as the hole lifetime. Substantial resources were invested in modeling the thermodynamics and shape of the hole over time to optimize hole lifetime and fuel consumption (Greenler and others, 2014).
The EHWD was designed to accomplish this challenging task, and was continually refined over the course of IceCube construction. At the project's end, the EHWD had drilled 86 holes, each nominally $60 \mathrm{~cm}$ in diameter and $2500 \mathrm{~m}$ deep, in seven field seasons ( 21 months total time). Peak performance occurred in the 2009/10 season with 20 holes drilled (early November to mid-January). This paper outlines the functional description of the EHWD while pointing out important lessons learned.

\section{SYSTEM OVERVIEW}

\section{Design}

The highest-level EHWD system design requirements were to:

deliver 80 boreholes, each $60 \mathrm{~cm}$ diameter and $2500 \mathrm{~m}$ deep (actually delivered 86 holes),

complete drilling and instrumentation deployment in seven field seasons (2004-11),

withstand the South Pole environment (average austral summer temperature $-33^{\circ} \mathrm{C}$, winter storage minimum temperature $-80^{\circ} \mathrm{C}$, altitude $\sim 3000 \mathrm{~m}$ ),

stay compatible with South Pole logistics (all large cargo and fuel transported by LC-130 aircraft),

simultaneously support deployment of in-ice instrumentation (to streamline the drilling-deployment flow),

minimize drill time and fuel consumption, and

maintain safe and predictable operations.

Basic EHWD system characteristics are listed in Table 1. The design philosophy for the EHWD was to leverage and build upon the drilling experiences of AMANDA (Antarctic Muon and Neutrino Detector Array) (Koci, 1994, 2002; AMANDA Collaboration, 2001), the prototype detector that served as a proof of principle for IceCube. This was accomplished by 
Table 1. EHWD system characteristics

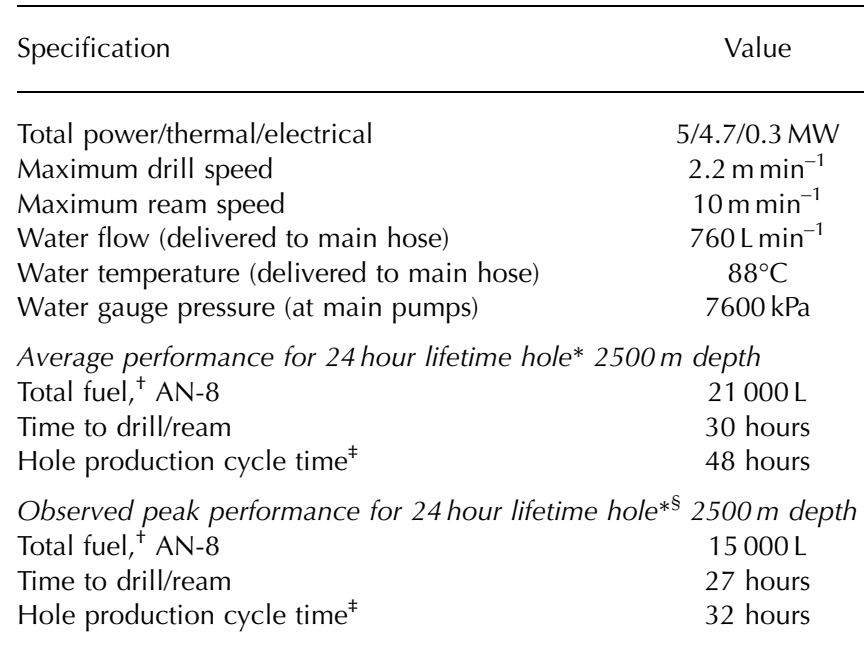

*Hole diameter remains $>45 \mathrm{~cm}$ for 24 hours after completion of drilling. ${ }^{\dagger}$ Includes deep drilling/reaming and firn drilling.

${ }^{\ddagger}$ Elapsed time from start of one hole to start of next hole.

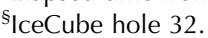

reusing equipment where appropriate, recruiting expertise and incorporating the following major enhancements:

doubled thermal capacity (from 2.3 to $4.7 \mathrm{MW}$ ),

continuous drill hose on a single hose reel (eliminating the need to add/remove hose segments throughout drilling/reaming),

extensive system automation,

two drilling structures (allowing for streamlined drillingdeployment flow),

modular design,

high-efficiency water heaters (to reduce fuel consumption), and

improved drilling strategy (optimizing hole shape to avoid over-drilling the borehole diameter and wasting fuel).

\section{Layout}

The EHWD system was implemented across two separate sites (Fig. 1). The seasonal equipment site (SES) provided electricity and a stable supply of hot pressurized water, and the tower operations site (TOS) was where the hole was drilled. The two sites were linked by long cables and insulated hoses.

The SES was composed of generators, water tanks, pump and heating buildings, a central control building, mechanical and electrical shops, spare parts storage, and system Rodwell. All the equipment was packaged into customized ISO (International Standards Organization) shipping containers manufactured by Sea Box Inc., each sized to fit into an LC-130 aircraft and tailored to its specific building functions. These packaged containers were called mobile drilling structures (MDS). Hoses and cables connected SES subsystem buildings together, and, wherever possible, custom electrically heated hoses were installed, providing an effective freeze mitigation strategy.

The TOS included the drill tower and attached operations building as well as the hose and cable reels. There were two

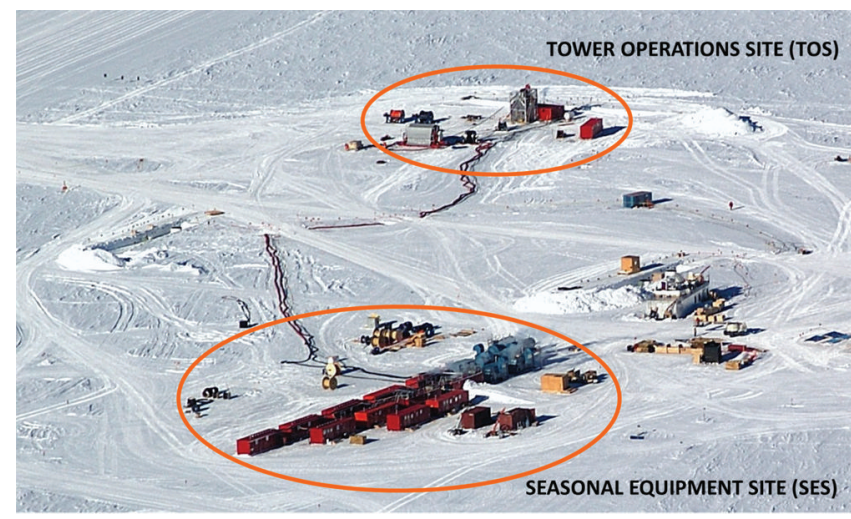

Fig. 1. Aerial view showing the full EHWD system.

towers and one set of drill reels. After drilling, drill reels were moved to the next hole location, where the second tower had already been staged. The first tower stayed at its existing location to support deployment of the instrumentation. Once deployment had finished, the first tower could be moved to the next location while drilling at the second tower was underway. This leapfrog sequence of the tower structures reduced hole turnover time and allowed for nearly continuous drilling operations.

Due to the massive size and complexity of the SES, it remained stationary throughout each drill season. At the end of the drill season, the SES was decommissioned and repositioned within a virgin sector of the IceCube array, staged for the following drilling season. The distance between the SES and TOS had a practical limit, referred to as reach, which defined the boundary of a seasonal drilling sector. Reach of the EHWD was estimated to be $450 \mathrm{~m}$, limited by pressure and voltage drop through the SES-TOS link. During the last two seasons of IceCube construction the SES supported two drilling sectors from the same SES location, demonstrating a reach of $430 \mathrm{~m}$.

\section{System architecture}

Much of the thermal system shared an architecture common to most hot-water drills (Koci, 1984; Makinson, 1994; Craven and others, 2002). Figure 2 shows the system water schematic. Water from storage reservoirs (water tanks 1 and 2 (WT1 and WT2)) is pumped (high-pressure pump (HPP)) at $760 \mathrm{Lmin}^{-1}$ and $7600 \mathrm{kPa}$ gauge pressure through heaters (main heating plants 1 through 4 (MHP1-4)) and heated to a maximum temperature of $88^{\circ} \mathrm{C}$ (the boiling point at South Pole altitude), then through a hose wound onto a hose reel (drill supply hose reel (DSHR)), and finally through a nozzle at the drill head tip. A submersible return water pump (RWP) is positioned at the top of the water column in the hole and recirculates water back to the reservoirs, closing the main loop. Additional secondary subsystems maintain the water storage in the reservoirs: A pre-heat system (PHS) controls the temperature and level of WT2, the stable reservoir, while the Rodwell system (RWS) is responsible for providing make-up water to the system and controlling the temperature and level of WT1, the less stable reservoir. The RWS provides make-up water from a subsurface well called a Rodriguez well, or Rodwell (Schmitt and Rodriguez, 1963; Lunardini and Rand, 1995), and is responsible for maintaining this well over the course of a drilling season. Generator waste-heat recovery is also managed by the RWS. 


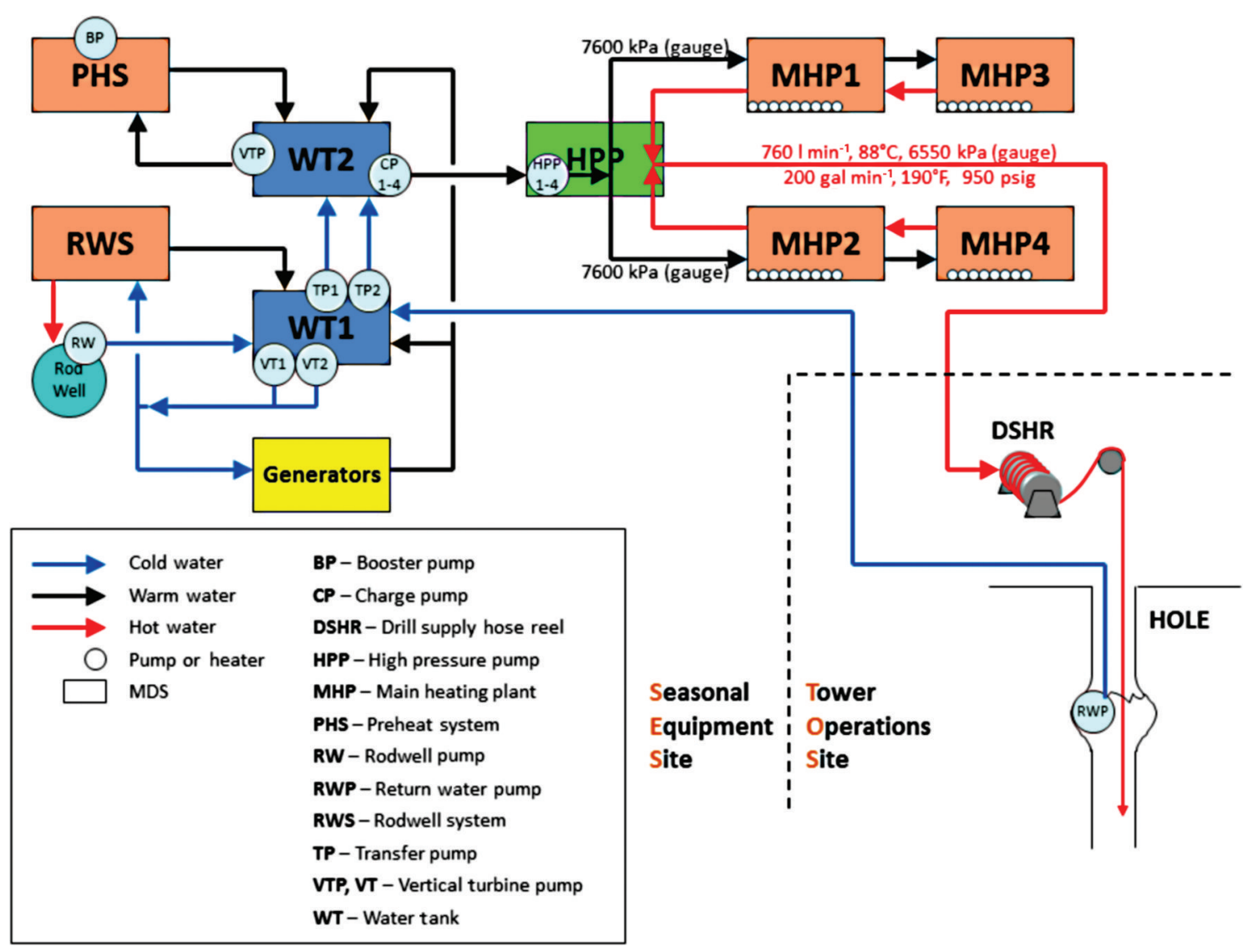

Fig. 2. System water schematic for the EHWD.

\section{THE PRIMARY WATER LOOP}

\section{Water tanks (WT1 and WT2)}

Two shipping containers were sealed on the inside with welded stainless-steel paneling, and the walls were filled with foam insulation. Each water tank provided $38000 \mathrm{~L}$ of capacity $(76000 \mathrm{~L}$ total). Two sets of large trapdoors were centrally located on the top for dumping snow and for general access. On both ends, a screened pump bay provided the first level of system filtration; this was important for protecting the pumps and system from larger debris sometimes mixed in with the snow. WT1 was accompanied by a snow ramp that allowed for large equipment - as big as a Caterpillar 953 - to dump snow directly into the tank.

\section{High-pressure pumps (HPP)}

The HPP building housed four Myers D65-16 high-pressure positive displacement triplex piston pumps, each capable of $246 \mathrm{~L} \mathrm{~min}^{-1}$, providing near-full-capacity flow with only three pumps. Nominally, all four pumps ran at $190 \mathrm{~L} \mathrm{~min}^{-1}$ and $7600 \mathrm{kPa}$ gauge pressure. The pumps were driven by Baldor SuperE ${ }^{\circledR} 45 \mathrm{~kW}$ induction motors and controlled by Unico vector motor drives. Water was supplied to each pump from its own submersible charge pump in WT2, maintaining the intake gauge pressure of the large pumps above $276 \mathrm{kPa}$ to prevent cavitation. Pressure switches on the intakes served as interlocks for the high-pressure pumps. The submersible pumps, standard $1.5 \mathrm{~kW}$ Grundfos groundwater supply pumps, were outfitted with custom polycarbonate shrouds to enhance motor cooling. The highpressure pumps were equipped with pressure relief valves that vented into a heated hose leading back to WT2; however, the primary freeze protection scheme for this critical line was a throttled leak flow $\left(7-20 \mathrm{~L} \mathrm{~min}^{-1}\right)$ bled from the charged intake side of each high-pressure pump. Controls and safety interlocks were implemented into the pump drives, including torque limiting (used as the primary overpressure safety), fast shutdown on detection of rapid pressure loss (indicating a burst hose), and forced-air ventilation control of the HPP building to maintain motor and room temperatures.

\section{Main heating plants (MHPs)}

The EHWD had 35 main water heaters plumbed in parallel, contained within four MHPs. Each heater was capable of $125 \mathrm{~kW}$ output, and powered by a fuel-fired burner unit consuming $\sim 13 \mathrm{Lh}^{-1}$. Since heating the drilling water accounted for the majority of consumed fuel, significant effort was put into maximizing thermal efficiency of the water heaters (Benson, 2008). High efficiency was achieved with modifications to a standard off-shelf high-pressure Whitco hot-water heater traditionally used in the car wash industry. A molded ceramic combustion liner was installed to increase temperature and improve flame quality by insulating and reflecting radiation back into the combustion region. A secondary stainless-steel condensing heat exchanger was also added. The heaters were configured as counter-flow heat exchangers.

The enhancements raised the standard off-shelf thermal efficiency of $78 \%$ (lower heating value) to $93 \%$ (higher heating value) and saved the project $>379000 \mathrm{~L}$ of fuel. The addition of the condensing heat exchanger generated $9500 \mathrm{~L}$ per hole of condensate from the exhaust gases. This condensate was collected, cleaned and neutralized, then 


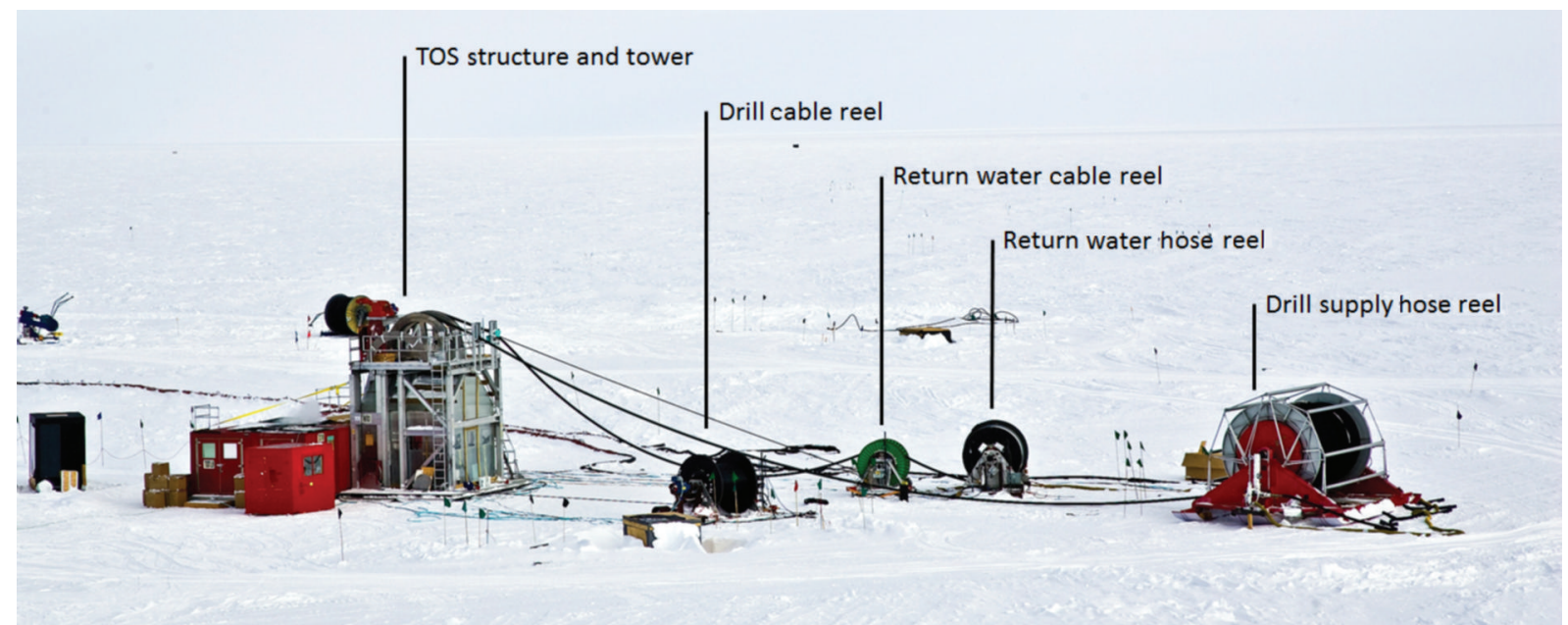

Fig. 3. TOS structure and tower, drill cable reel, return water reels, and drill supply hose reel.

reintroduced into the system as a source of make-up water. Although this could provide up to $15 \%$ of the required make-up water, the additional work to maintain the collection system and neutralize the condensate seemed to outweigh the benefit. Other means of disposal would be considered in the future.

Redundant levels of safety were implemented on the heaters. Heater output temperature was instrumented with three levels of safety devices (thermocouple monitored by control system; local thermostat and thermocouple; overtemperature switch), and flow with two levels (turbine flow meter monitored by control system; local differential pressure switch across heater). Note that the flow and temperature devices work in conjunction with each other, since a satisfied flow is required to transport heated water past the temperature sensors.

The primary heater coils were schedule 80 steel pipe. These corroded, resulting in build-up of a muddy iron oxide film on all internal wetted surfaces and in the borehole water column. In retrospect, the project should have opted for stainless coils for both heat exchangers to avoid the iron oxide accumulation.

Downstream of the MHP buildings, the heated water was routed back to the HPP to combine the flows into a simple manifold; measure the pressure, flow and temperature; and finally direct the water to the TOS via a long insulated $64 \mathrm{~mm}$ inner diameter (i.d.) ethylene propylene diene monomer (EPDM) rubber surface hose.

\section{Tower operations site (TOS) surface equipment} (Figs 3 and 4)

The primary function of the TOS during deep drilling was to deliver hose and cable to the hole at an appropriate rate for creating the desired hole shape. With the hose and cable deployed to $2500 \mathrm{~m}$, there was $118 \mathrm{kN}$ of equipment load, but only $29 \mathrm{kN}$ of downward load exerted on the drill tower

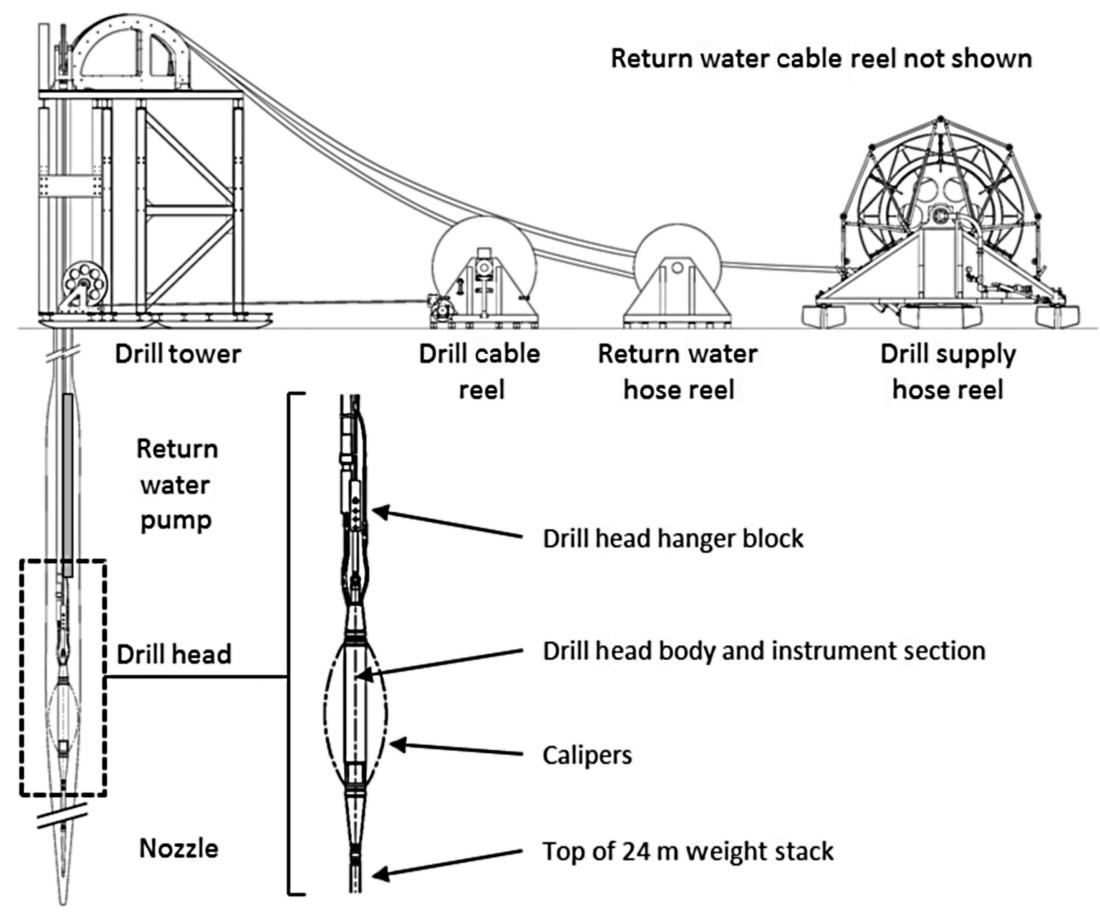

Fig. 4. TOS surface and downhole equipment. 
due to buoyancy. While the majority of this load came from the $2500 \mathrm{~m}$ of $64 \mathrm{~mm}$ i.d. aramid-reinforced EPDM rubber hose (custom-made by IVG Colbachini Spa), the hose itself could only reliably carry $7 \mathrm{kN}$ when pressurized and bent over the TOS crescent. Therefore, most of the load needed to be carried by the $25 \mathrm{~mm}$ outer diameter (o.d.) Vectran ${ }^{\circledR}$ reinforced Hytrel ${ }^{\circledR}$-jacketed power and communication cable (manufactured by Cortland Cable) which had a $45 \mathrm{kN}$ working load. A special high-performance tape (Nitto P-212) periodically wrapped around the hose and cable during drilling (removed during reaming) transferred the load of the hose to the cable. These tape bands were a simple solution that worked extremely well.

The DSHR held the full-length hose, composed of twentytwo $122 \mathrm{~m}$ sections. This giant reel had a mass of $45000 \mathrm{~kg}$ with water-filled hose. The main drill cable reel held a onepiece cable, could spool with $45 \mathrm{kN}$ of load and had a multichannel electrical slip ring to supply power and to communicate with the drill head while rotating. The reel drum motors were driven by Unico vector drives with custom logic that used feedback from payout encoders and load cells to move the cable at the commanded drill speed while maintaining hose tension consistently around $7 \mathrm{kN}$. Another set of drives controlled the level wind motors for the reels. The speeds of these motors were electronically geared to their respective drum motors, using drum and payout encoders to correct for diameter change of the wrapped hose and cable. System emergency stop (e-stop), local reel stops, and programmable limits in the control system and motor drives immediately initiated a fast stop of the reels if activated, stopping the motors and engaging large disk brakes. The hose was routed from the reel up to the top of the tower and over a crescent into the hole. The height of the tower was limited by air-traffic requirements for drilling in close proximity to the South Pole skiway, so a half-circle crescent with a belt of shaped plastic blocks supported the hose over a $1.4 \mathrm{~m}$ radius. There were segmented aluminum strain relief assemblies at the hose fittings to help carry the bending load as the fittings passed over the crescent. The cable was routed through $0.9 \mathrm{~m}$ circular sheaves located on the tower base and upper platform.

Cold water from the top of the hole was pumped by a $37 \mathrm{~kW}$ Grundfos submersible pump and returned to the SES through another surface hose. The pump was powered and supported by a combo cable containing strength members and signal wires for downhole temperature and pressure transducers. The return water cable reel had an electrical slip ring for power and signal lines. The return hose and cable went over a crescent at the top of the tower. At $3.7 \mathrm{~m}$, the pump was the longest single piece lowered down the hole and established the inside height requirement for the tower. The pump followed the drill head into the main borehole to a depth of $60-80 \mathrm{~m}$. Towards the end of drilling, the pump was lowered to maximum depth $(80 \mathrm{~m})$, and the top of the water column was pumped out to recover extra water. If needed, hot water was back-flushed through the pump during its removal to ream any narrow sections in the upper $80 \mathrm{~m}$ of hole.

The tower itself was an aluminum welded and bolted structure with a multi-wall transparent polycarbonate shelter with skis under the deck. It was towed as a unit from hole to hole. The upper deck had the main hose crescent, return hose and cable crescent, and main cable sheave assemblies with associated payout encoders and load cells. It also had a $22 \mathrm{kN}$ tower hoist that was used to assemble the weight stack and drill head, deploy the return water pump, and aid in deployment of the DOMs. The tower was connected to a double-wide MDS that housed motor drives, a control room, an instrumentation staging area and a drill equipment area. With the exception of the DSHR, all the reels were anchored into the snow so they did not slide toward the hole during use. The weight of the DSHR was sufficient to maintain its position.

\section{Tower operations site (TOS) downhole equipment (Fig. 4)}

The drill head delivered the hot water to the ice at the bottom of the hole. On many hot-water drills, the hose terminates in a simple nozzle. IceCube chose to have instrumentation in the drill head to measure hole diameter, supply-water temperature, supply-water pressure, hole-water column pressure, hole-water temperature, tilt relative to vertical, horizontal magnetic field (for rotational angle), and load exerted by the drill head on the hose. Three drill heads were built, one of which was also equipped to make acceleration measurements. The data from the instrumentation package were communicated to the surface using RS-485 over the drill cable and were extremely valuable at the beginning of the project in helping understand the drilling process.

The drill head load cell provided direct feedback for when the drill was being advanced faster than the ice was melting. A drop in drill head load indicated that some mass of the drill head and weight stack was being carried by the ice, necessitating a reduction in drilling rate. Out of water, the drill head by itself and with the weight stack weighed 227 and $795 \mathrm{~kg}$, respectively, and the assembled weight when submerged was $522 \mathrm{~kg}$.

The diameter of the hole was measured by eight caliper springs symmetrically located around the drill body. Hole diameters of $29-76 \mathrm{~cm}$ could be measured. The diameter measurement was particularly important during the reaming phase, where it was used as an input for determining ream speed from the drill strategy charts. For a given depth, comparison of the diameters measured during the drilling and reaming phases provided validation for the drilling models (Greenler and others, 2014), and over time this allowed fine-tuning of the ream which yielded significant fuel savings through optimization.

The supply-water temperature at the drill head was useful in determining the actual energy delivered to the ice. The temperature of the drilling water can change significantly between the SES and the drill tip. The primary temperature drop is from cooling of the water in the hose that is submerged in the water-filled hole. The temperature drop is very predictable for normal drilling at constant flow. However, when the system is stopped for some time or heaters trip offline, it can be difficult to predict the nozzle exit temperature. There is a $\sim 15 \mathrm{~min}$ delay between temperature drop at the SES and temperature drop at the nozzle at normal operating flow. Having direct supply-water temperature measurement at the drill head provided accurate information on energy delivered, allowing for appropriate setting of the drill speed.

The pressure in the hole outside the drill head was one of several redundant measures of the depth of the drill (the drill cable payout was the most reliable and accurate measure of drill depth). Initially the stretch of the cable and hose together was not well understood, and the water head pressure (with appropriate consideration for water density 
variation due to temperature and depth) was compared against cable payout to calibrate the stretch.

The horizontal deviation of the borehole axis from top to bottom was less than $\pm 2 \mathrm{~m}$. This was concluded from a dead-reckoning analysis using drill head tilt and rotation data. A heavy stainless-steel weight stack hung beneath the drill head produced a pendulum effect to keep the drill vertical. A small error in the verticality of the weight stack was further compensated for by a slow rotation of the drill head due to hose twist. The $24 \mathrm{~m}$ length of the weight stack was also needed to allow time for heat transfer from the hot water into the ice to open the hole enough for the $29 \mathrm{~cm}$ diameter instrumented drill body to pass. The weight stack was assembled from a tapered front piece that housed the nozzle, a single $102 \mathrm{~mm}$ o.d. $\times 3 \mathrm{~m}$ section, and five $127 \mathrm{~mm}$ o.d. $\times 3 \mathrm{~m}$ sections.

High heat transfer was achieved in front of the nozzle by the impinging water jet, which also swept cold meltwater out of this critical region. Initially, a $32 \mathrm{~mm} 0^{\circ}$ nozzle was used, and heat transfer limited drilling to $\sim 1.5 \mathrm{~m} \mathrm{~min}^{-1}$. System pressure limits permitted a nozzle as small as $18 \mathrm{~mm}$ $\left(0^{\circ}\right.$ spray angle), providing a jet velocity of $45 \mathrm{~m} \mathrm{~s}^{-1}$ and allowing drill rates up to $2.2 \mathrm{~m} \mathrm{~min}^{-1}$. Beyond these rate limits, vertical oscillations of the downhole equipment occurred, which can lead to mechanical failures.

\section{SECONDARY WATER SUBSYSTEMS}

\section{Rodriguez well system (RWS)}

The RWS was responsible for (1) maintaining Rodwell makeup water, (2) maintaining WT1 level and temperature (5$15^{\circ} \mathrm{C}$ ) and (3) controlling the generator waste-heat recovery loop. Referring again to Figure 2, two $5.6 \mathrm{~kW}$ vertical turbine pumps (American Turbine Pump) on WT1 supplied water for RWS operations. Water directed to the RWS was first heated through a bank of nine small Whitco Stinger water heaters ( $\sim 65 \mathrm{~kW}$ output each at $85 \%$ higher heating value efficiency, counter-flow configuration). The heated water could be routed back to WT1 for maintaining tank temperature or sent to the Rodwell. Warm water returning from the generator waste-heat exchangers was split between WT1 and WT2.

The EHWD Rodwells were melted cavities of stored water in the ice at a depth of $\sim 60 \mathrm{~m}$ or more. Hot water was supplied to sustain a slow growth of the cavity, reaching volumes on the order of hundreds of thousands of liters, and the melted ice was recovered to supply the make-up water. An A.Y. McDonald $7.5 \mathrm{~kW}$ submersible pump returned the water from the Rodwell back to WT1 via the RWS. In theory, $\sim 57000 \mathrm{~L}$ of make-up water was required for each IceCube hole, but in practice $95000 \mathrm{~L}$ per hole was required due to percolation loss into the lower firn layers at the top of the hole and water spent during the beginning and completion phases of each hole.

Careful monitoring and management strategy of the Rodwell played a large role in fuel savings later on in the project. Real-time Rodwell volume and growth rate estimates were made from analysis of flows, temperatures and levels and by using a number of field tools, including a water level sounder, sinking measures and sonar. This informed day-to-day strategic decisions on Rodwell management and optimization. All but one season required relocation of the SES, so an entirely new Rodwell was required almost every year. The general goal was to rapidly develop a mature Rodwell early in the season and then tailor the maintenance throughout drilling to minimize the amount of water remaining at the end of the season.

\section{Preheat system (PHS)}

The PHS was responsible for (1) maintaining WT2 level and temperature $\left(15-25^{\circ} \mathrm{C}\right)$ and (2) system filtration. A stable WT2 temperature was important for consistent drilling since temperature fluctuations propagated all the way to the drilling nozzle. Keeping WT2 relatively full provided a large thermal mass that helped improve overall WT2 temperature stability. One $5.6 \mathrm{~kW}$ vertical turbine pump (American Turbine Pump) located on WT2 supplied water to the PHS, and two $1.5 \mathrm{~kW}$ Grundfos submersible pumps transferred water from WT1 to WT2, providing WT2 level control. The flow supplied to the PHS was split between a bank of four large $125 \mathrm{~kW}$ Whitco water heaters and the filtration system. Heated water was returned to WT2. The filtration system consisted of a Lakos centrifugal filter, to spin out large particulates, and three FSI bag filters plumbed in parallel, typically running a $25 \mu \mathrm{m}$ filter. The filtered water was returned to WT2. System condensate collection and processing was also done in the PHS. Both the filtration and WT2 control worked well. Cycling of WT2 temperature was an occasional side effect of the large discretized heat input from the PHS heaters but could easily be balanced by adjusting generator waste-heat water between WT1 and WT2.

\section{OTHER SUBSYSTEMS}

\section{Generators and electrical distribution}

During drilling, $300 \mathrm{~kW}$ of electrical power was generated by two AN8-fired turbocharged diesel engines with $480 \mathrm{~V}$ a.c. three-phase generators. The drill included three generators to always allow for repair or routine maintenance on one of them. The altitude at the South Pole resulted in the generators being derated from $225 \mathrm{~kW}$ to $165 \mathrm{~kW}$, and in practice it was difficult to maintain reliability above $150 \mathrm{~kW}$. About $33 \%$ of the energy content of the fuel was converted to electricity. An additional $40 \%$ of the fuel's energy $(200 \mathrm{~kW})$ was recovered as heat from the engine coolant and exhaust system into water circulated from WT1. This worked well during steadystate drilling, but the switch to conventional radiator cooling often was not fast enough to prevent engine overheating when the WT1 water flow was stopped. When less power was required during idle (the phase between holes), only one generator was needed.

A power distribution module (PDM) housed monitoring, load sharing, generator switching and manual synchronization equipment. The power from all three generators passed through PDM breaker panels and into a connector panel for cables distributed to each MDS. The heavy-duty electrical cables had to withstand outdoor conditions during use and storage and were custom-made with thermoplastic elastomer (TPE) insulation and jackets to maintain flexibility and minimize cracking while handling in extreme-cold conditions.

\section{Computers, control network and motor drives}

Automation of the EHWD was critical for achieving smooth, reliable operations and enhanced safety. Control of SES functions and all communications was centralized in the drill control center (DCC), while TOS operations were maintained locally. However, either location could control the other. A user interface, organized into tabs according to 
subsystem, provided users with system information and control of most equipment. A Linux-based control server in the DCC communicated with hardware and instrumentation on 16 multi-drop RS-485 networks, while each TOS had its own control server and four RS-485 networks. The SES and TOS control servers were linked with DSL over twisted pairs and altogether managed $>500$ sensors/actuators and 32 Unico vector motor drives. To keep the vector motor drive outputs from creating electrical noise in nearby signal cables, all cabling was shielded, and resistor-capacitor (RC) filters were implemented where shielding alone did not effectively block the noise.

Calibrations, conversions, safety limits and network health were all maintained within the control system. A number of control algorithms were written, including auto start-up sequencing, hose tension control, critical system alerts and response, and automatic drill/ream speed control. Many of these controls were implemented in close conjunction with custom motor drive logic. All data were written to a log file, providing valuable data history that could actively be graphed within the user interface or later utilized for analysis. A wireless network was set up to transmit key variables to personal digital assistants (PDAs) that operators could carry with them while tuning the system. The private drill network connected to the South Pole Ethernet via firewall, providing data logging off-site, along with internet and VolP telephone service.

\section{Emergency stop and reel stop systems}

High-visibility red slap switches were positioned throughout the system and offered activation of an emergency stop (estop), which would result in:

halting all equipment motion,

removing drive power from all reels and hoists,

applying brakes on all applicable reels and hoists,

halting the high-pressure pumps, and

closing off fuel flow to burners and furnaces.

The generators and charge pumps continued to run during an e-stop. Electrical power is critical in an emergency situation, and the electrical distribution has its own levels of safety shutdowns. By allowing the charge pumps to continue running, water flow was maintained through the heaters to carry away residual heat. This flow was also aided by natural siphoning downhole during active drilling. The system was designed so that both an open or shorted connection would result in e-stop activation. When a slap switch was depressed, its location was registered on the control system so that operators could be quickly dispatched to the correct location.

The TOS and RWS had similar but localized reel stop systems in addition to e-stops. This safety feature only halted local reels and hoists and applied their brakes, and could be activated by yellow slap switches, pull cords on the reels, hard-limit switches on the level winds, or by the control system.

\section{Fuel system}

Fuel was delivered to the SES in $19000 \mathrm{~L}$ fuel tanks. At least three of these tanks were on-site at all times, with one always online. These tanks supplied a $1200 \mathrm{~L}$ gravity-feed day tank from which fuel was delivered throughout the SES. An automatic filling and level alert system maintained day tank level between prescribed limits. The day tank delivered fuel at $14 \mathrm{kPa}$ gauge pressure gravity head through dedicated hoses for each building from a manifold system. At each building inlet, there was a quick-disconnect valve and shutoff solenoid tied into the e-stop system, and a marine-grade Racor fuel filter and water separator. Every water heater and furnace was equipped with a fused fail-safe fuel shut-off valve. The small fuel pumps on the burner units were not capable of overcoming pressure drop to return fuel to the day tank, so a single-line fuel delivery system was used. This led to problems of air getting trapped in the lines and bringing down the system. Air traps made of clear tubes were placed at high spots throughout the system. The trapped air could be monitored and purged as needed. The original day tank was configured with a top-feed siphon pipe, and although the site tubes largely solved the air problem, switching to a bottomfeed day tank completely eliminated it.

\section{Independent firn drill}

At the South Pole, the firn (a layer at the surface of lowerdensity snow transitioning to ice) does not hold water until it reaches sufficient density at $35-40 \mathrm{~m}$ below the surface. The deep drilling method relies on the water to pool for longduration heat transfer to the borehole wall. This process does not work in firn. Early in the project, a large coneshaped aluminum vessel filled with hot water was used to melt the firn. While this worked, it was very slow, even with substantial water flow out of a nozzle at the bottom. To improve heat transfer, the aluminum vessel was replaced with coils of $13 \mathrm{~mm}$ o.d. copper tube wound into the shape of a cone. High flow rate through the tube ensured good heat transfer and improved the drilling rate enough that it could be used in a closed-loop configuration. This reduced water usage, fuel consumption, and demand for water from the Rodwell. This method, however, still took a significant amount of time because plumbing had to be reconfigured between firn and deep drilling.

An independent firn drill (IFD) was built to allow for predrilling the firn holes in parallel with the deep drilling (Fig. 5, left and middle). This reduced the time pressure on firn drilling while simultaneously increasing the time available for deep drilling. The net result was an increase from 13 holes to 18 or more holes drilled in a season. The IFD was designed to minimize manpower requirements by utilizing electric heat and a propylene glycol water mixture for heat transfer fluid. The same copper coiled cone design was used (Fig. 5, middle). The system was left running unmanned with periodic checks, and a drill rate of $2 \mathrm{~m} \mathrm{~h}^{-1}$ was reliably achieved while consuming about $1100 \mathrm{~L}$ of fuel per firn hole.

\section{OPERATIONS}

Each drilling season started with a staggered arrival of drill crew members while the SES and TOS were excavated and commissioned. Season start-up tasks included SES and TOS warming and hook-ups, reinstallation of do-not-freeze equipment (e.g. motor drives, sensors and some rubber/ gaskets), generator commissioning, safety checkout and system tuning, seed water delivery and Rodwell development. This phase typically took 4 weeks, 3 of which had a full crew of $\sim 30$ drillers. Once seed water was delivered, the transition was made to around-the-clock operations spread across three 9 hour shifts. 

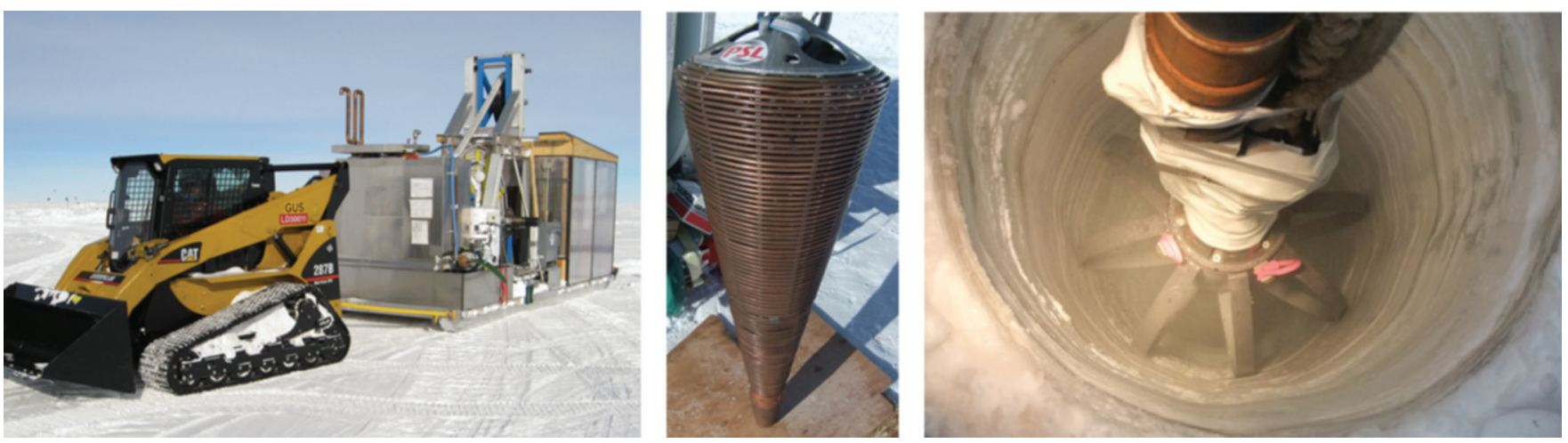

Fig. 5. (Left) independent firn drill sled; (middle) independent firn drill copper coiled cone; (right) IceCube drill head descending into a firn hole drilled by the independent firn drill.

The production drilling sequence was to drill, ream, and move to the next location. Independent firn drilling stayed ahead of deep drilling by no fewer than a couple of holes, and often the Rodwell and first few holes of the season had already been firn-drilled the prior season. The phase between holes, called idle, was characterized by minimal flow through the system and fine-tuning of Rodwell management strategies. The idle phase also included regular maintenance tasks (equipment inspections, scheduled maintenance, and preparations for next hole) and, of course, deployment of IceCube instrumentation. Hole production rate was 48 hours per hole on average, and the quickest cycle time was 32 hours.

System shutdown would begin $\sim 2$ weeks before season's end. Shutdown tasks included flushing the system with propylene glycol, blowing out the plumbing with compressed air, removing do-not-freeze equipment for warm storage, storing the TOS structures and other support equipment, and finally moving the SES into location for the following season.

During steady drilling operations, a minimum of four people were needed to operate the drill (drill control center, SES float, TOS control, TOS float), but a full shift was required to move hole locations and aid in deployment. Minimum shift size was nine team members, which allowed for one sick worker and a four/four split lunch. A critical part of the staffing plan was to have a good spread of expertise on all shifts, including a shift lead and deputy lead comfortable with all aspects of the system and its operation, a safety officer (duty of the deputy lead), an electronics expert, a heater expert, a software expert and mechanically proficient technicians. The most important thing IceCube did to assure successful drilling operations was put a strong focus on retention of experienced drillers and talent.

A strong safety culture was an essential aspect of drilling and deployment operations. Annually reviewed safety processes included a safety manual, 34 standard operating procedures, 18 hazard analyses and a series of checklists. In the field, safety briefs, emergency management exercises, near-miss incident reporting, and peer safety audits became a matter of course. Off the ice, a 2 week driller training course was organized each year to highlight system technical updates, discuss plans for the coming season, and provide further safety and first-aid training. As a result of this safety culture, IceCube had only four lost time drillingrelated safety incidents in $\sim 52$ on-ice person-years.

\section{PERFORMANCE}

Table 1 lists observed average and peak performance to drill a hole with a 24 hour lifetime (IceCube's target lifetime was reduced from 37 hours early in the project to a minimum of 24 hours). Figures 6 and 7 summarize EHWD performance over the course of IceCube construction. The trends clearly illustrate early difficulties followed by continual improvements derived from equipment reliability and crew experience.

Figure 7 shows seasonal overlays of depth versus time, aligned at hole bottom. A wider spread and zones of flatness or reverse direction indicate issues that spent time and fuel. The lessons highlighted throughout this paper allowed for the peak production shown in 2009/10 (20 holes). We believe that this production level is a firm and fundamental upper limit for this drilling system.

As stated, fuel efficiency was a primary technical design driver. Major fuel-saving measures were engineered into the initial design, but measures taken throughout the project yielded additional savings. These included independent firn drilling that saved valuable water, more aggressive targets for hole lifetimes as confidence in the drilling models grew, more efficient idle and Rodwell management strategies, careful monitoring and reporting on fuel usage, and fostering of fuel consciousness among the crew. The smallest amount of fuel used to drill a hole was $15000 \mathrm{~L}$ (2009/10, hole 32), almost half of the project's $27000 \mathrm{~L}$ per hole baseline.

\section{CONCLUSION}

With the EHWD, we have demonstrated that is it possible to do large-scale production ice drilling in the Antarctic environment in a safe, efficient and predictable way. Critical components of IceCube's successful drilling campaign included a large engineering investment, steadfast year-toyear support to properly address lessons learned, a strong safety culture, and priority on retention of experienced crew members.

\section{ACKNOWLEDGEMENTS}

We thank the US National Science Foundation (NSF) for its generous support through grant OPP-0236449, and are grateful to the NSF Office of Polar Programs and the NSF Physics Division. We also thank the University of Wisconsin 


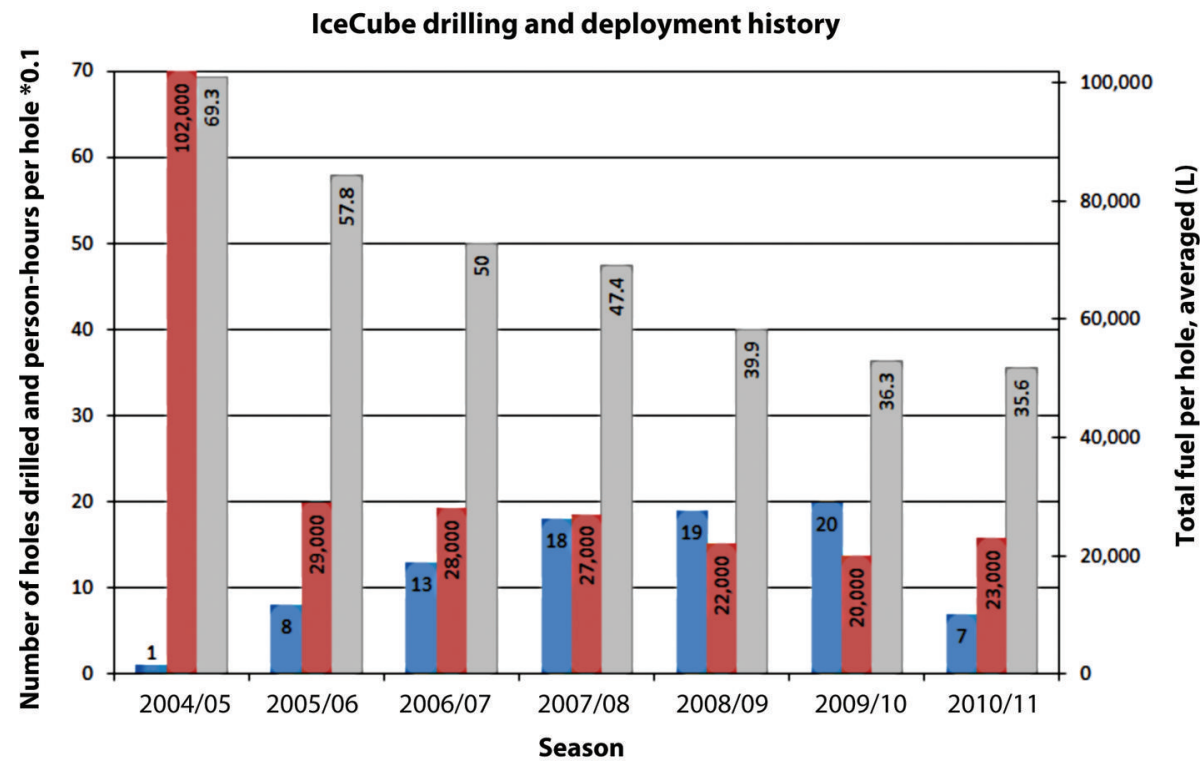

- Number of holes drilled

$\square$ Average person-hours per hole drilled and deployed ${ }^{*} 0.1$

- Total fuel per hole, averaged

Fig. 6. Seasonal performance of the EHWD.
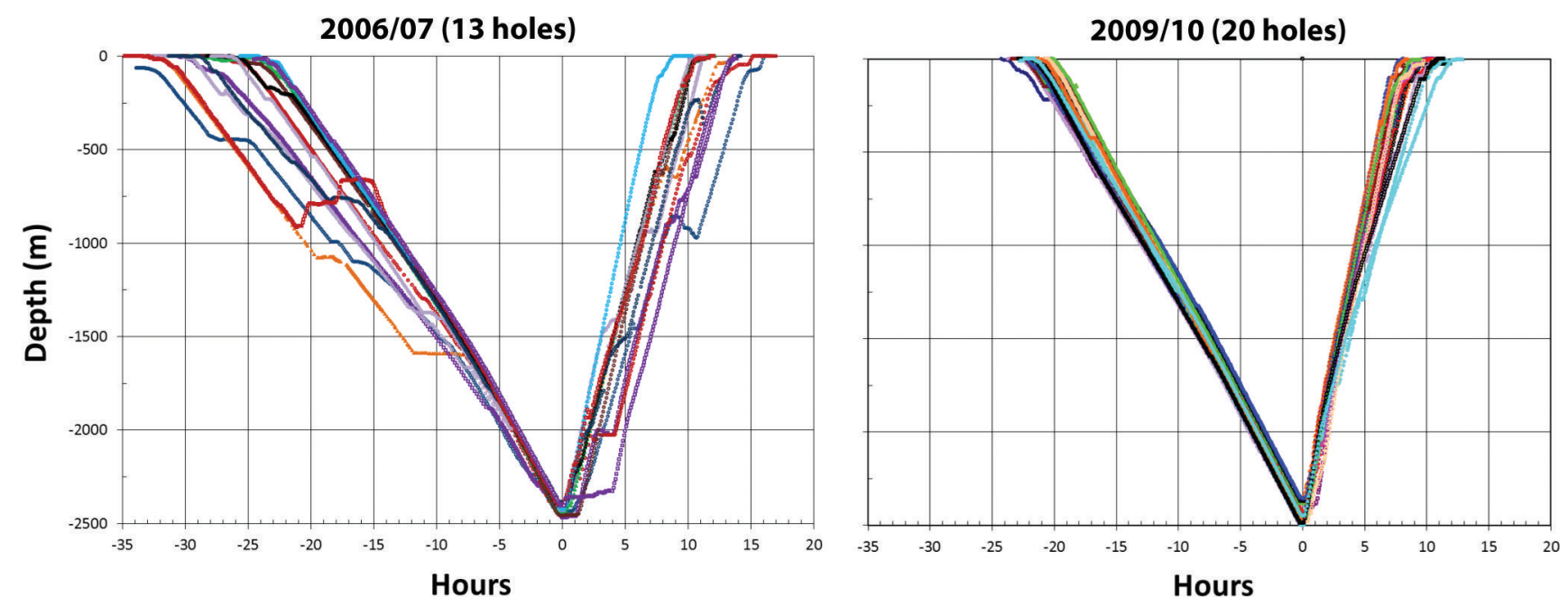

Fig. 7. Seasonal overlays of drilling depth versus time.

Alumni Research Foundation. We are grateful to Raytheon Polar Services Corporation for logistics and field support, and also to all of the drillers that helped make IceCube construction a success.

\section{REFERENCES}

AMANDA Collaboration (2001) Observation of high-energy neutrinos using Cerenkov detectors embedded deep in Antarctic ice. Nature, 410(6827), 441-443 (doi: 10.1038/35068509)

Benson T (2008) Dynamic modelling of fuel-fired water heaters the IceCube Project's hot water drill thermal power source. (Master's thesis, University of Wisconsin-Madison)

Craven M, Elcheikh A, Brand R and Jones N (2002) Hot water drilling on the Amery Ice Shelf - the AMISOR project. Mem. Natl Inst. Polar Res., Special Issue 56, 217-225
Greenler L and 6 others (2014) Modeling hole size, lifetime and fuel consumption in hot-water ice drilling. Ann. Glaciol., 55(68) (see paper in this issue) (doi: 10.3189/2014AoG68A033)

Halzen F and Klein SR (2010) IceCube: an instrument for neutrino astronomy. Rev. Sci. Instr., 81(8), 081101 (doi: 10.1063/ 1.3480478)

IceCube Collaboration (2009) The IceCube data acquisition system: signal capture, digitization, and timestamping. Nucl. Instrum. Meth. Phys. Res. A, 601(3), 294-316 (doi: 10.1016/j.nima. 2009.01.001)

IceCube Collaboration (2013) Measurement of South Pole ice transparency with the IceCube LED calibration system. Nucl. Instrum. Meth. Phys. Res. A, 711(1), 73-89 (doi: 10.1016/ j.nima.2013.01.054)

Koci BR (1984) Hot water drilling in Antarctic firn, and freezing rates in water-filled boreholes. In Holdsworth G, Kuivinen KC and Rand JH eds. Ice Drilling Technology. Proceedings of the 
Second International Workshop/Symposium on Ice Drilling Technology, 30-31 August 1982, Calgary, Alberta, Canada. (CRREL Spec. Rep. 84-34) US Army Cold Regions Research and Engineering Laboratory, Hanover, NH, 101-103

Koci B (1994) The AMANDA project: drilling precise, largediameter holes using hot water. Mem. Natl Inst. Polar Res., Special Issue 49, 203-211

Koci B (2002) Wotan: a drill for IceCube. Mem. Natl Inst. Polar Res., Special Issue 56, 209-216
Lunardini VJ and Rand J (1995) Thermal design of an Antarctic water well. CRREL Spec. Rep. 95-10

Makinson K (1994) BAS hot water drilling on Ronne Ice Shelf, Antarctica. Mem. Natl Inst. Polar Res., Special Issue 49, 192-202 Schmitt R and Rodriguez R (1963) Glacier water supply and sewage disposal systems. In Symposium on Antarctic Logistics, 13-17 August 1962, Boulder, Colorado, USA. National Academy of Sciences-National Research Council, Washington, DC, 329-338 